\title{
Minimally Invasive Thoracoscopic Procedures - A Single Centre Experience
}

\author{
Rengarajan $\mathrm{R}^{1}$, Dr.Muthulingam $\mathrm{V}^{2}$, G Rajamani ${ }^{3}$, Raghul $\mathrm{M}^{4}$ \\ ${ }_{1,2,3,4}$ (Coimbatore Medical College Hospital , Coimbatore , India)
}

\begin{abstract}
VATS is principally employed in the management of pulmonary, mediastinal, and pleural pathology. Its main benefit has been the avoidance of a thoracotomy incision, which allows a shorter operating time, less postoperative morbidity, and earlier return to normal activity than with thoracotomy.Video-assisted thoracoscopic surgical (VATS) procedures are very safe and efficacious in paediatric patients of all age groups. Our study was undertaken to analyse the usefulness of thoracoscopy in Paediatric population in the management of various thoracic pathologies in relation to its feasibility, safety,efficacy and reliability and to compare its advantages over thoracotomy in relation to post operative pain, recovery,morbidity and cosmesis. This study retrospectively analysed the records of patients who had undergone thoracoscopic procedures for various pathologies during January 2001 to December 2015 at the Department of Paediatric Surgery, Coimbatore Medical College Hospital. The study population included cases of Empyema thoracis, Pyopericardium, Congenital Diaphragmatic hernia (CDH), Eventration, Bronchogenic cyst, Foregut Duplication Cyst, Lymphoma, Tracheo Esophageal Fistula. A total of 60 patients were included. Operating time, conversion rate, post operative intercostal drianage tube time, post operative recovery and complication rates were assesed. Thoracoscopy was found to be definitely superior to thoracotomy in the management of Empyema thoracis in relation to pain relief, morbidity, early recovery and requirement of blood transfusion. Pyopericardial patients ha better cosmetic results. Thoracoscopy helps better in sick children and the yield of mediastinal biopsy was extremely high. Cystic lesions of the lung were excised safely .Procedure like thoracoscopic esophageal atresia repair needed more operative time and expertise with specialized instruments. Complications encountered in thoracoscopy are usually minor.
\end{abstract}

Keywords: decortication, empyema thoracis , esophageal atresia ,Video-assisted thoracoscopic surgery, VATS

\section{Introduction}

Video-assisted thoracoscopic surgical (VATS) procedures are being used in children since 1970s. With the advent of smaller endoscopic instruments and improvement in video technology, more VATS procedures are being performed. These procedures are very safe and efficacious in paediatric patients of all age groups including new borns. Initially, the usefulness of thoracoscopy was limited to only biopsies, decortication and deroofing of pulmonary cyst. Today, more than 20 types of VATS procedure are introduced in infants and children. They mainly deal with disease of esophagus, lungs, mediastinal tumors, diseases of the diaphragm, pleura and pericardium. VATS obviously has certain advantages such as superior cosmetic results, prevention of functional disorders of the thorax, lesser post-operative pain and faster recovery. Endosurgery has a considerable learning curve. Future of the thoracoscopy in children depends upon creation of better and new instruments. With this background, the present study is intended to analyse, various thoracoscopic procedures performed in our institution, and examine the merits and demerits of this procedure.

\section{Aims of the study}

To analyse the usefulness of thoracoscopy in Paediatric population in the management of various thoracic pathologies in relation to its

Feasibility

Safety

Efficacy

Reliability

To compare its advantages over thoracotomy in relation to

Post operative pain

Recovery

Morbidity

Cosmesis

To compare our results with other studies. 


\section{Materials And Methods}

3.1 Design: This is a retrospective and prospective study analyzing various procedures performed at Coimbatore Medical College Hospital and the outcome of the various procedures were evaluated.

3.2 Study period: This study retrospectively analysed the records of patients who had undergone thoracoscopic procedures for various pathologies during January 2001 to December 2015.

3.3Study center: Study carried out at the Department of Paediatric Surgery, Coimbatore Medical College Hospital.

3.4 Subject: Totally 60 patients had undergone either diagnostic or therapeutic thoracoscopic procedures at our department during the study period.

3.5 Instruments Used:

Zero and 30 degree $4 \mathrm{~mm}$ telescope (Karl Storz)

30 degree $10 \mathrm{~mm}$ telescope ( Karl Storz)

Diathermy : Martin/Aesculop

Light sourse : Halogen

Camera : (Karl Storz)

Insufflator : $\mathrm{CO}_{2}-$ automatic

Monitor

Video recorder

3.6Hand instruments:

Interchangeable with laparoscopic procedures

3.7Technique:

All patients who were investigated and confirmed of their diagnosis were taken up for therapeutic procedures. All patients received general anaesthesia, controlled ventilation.

\section{Results and Discussion}

Lateral decubitus position with the side of the pathology remaining upwards. Dual lung ventilation used. Pneumothorax created with $\mathrm{CO}_{2}$ or atmospheric air. Number of ports varied according to the pathology and as operative analgesia as per need. per the need. No specialized instruments used. All patients received chest tubes following the procedure. Post The present study analyses various thoracoscopic procedures done in our Department and has reviewed the outcome of various procedures.

\begin{tabular}{|l|l|l|}
\multicolumn{4}{|l}{ Total number of case -60.} \\
\hline Diagnosis & Procedure & No. of patients \\
\hline Empyema thoracis & $\begin{array}{l}\text { Diagnostic thoracoscopy \& Open } \\
\text { decortication }\end{array}$ & 16 \\
\hline Empyema thoracis & Thoracoscopic debridement & 24 \\
\hline Pyopericardium & Window pericardiectomy & 6 \\
\hline CDH & Repair & 4 \\
\hline Eventration & Plication & 2 \\
\hline Bronchogenic cyst & Excision & 2 \\
\hline Foregut Duplication Cyst & Excision & 2 \\
\hline Lymphoma & Mediastinal node biopsy & 2 \\
\hline TEF & Repair & 2 \\
\hline
\end{tabular}

I. CHART - 1

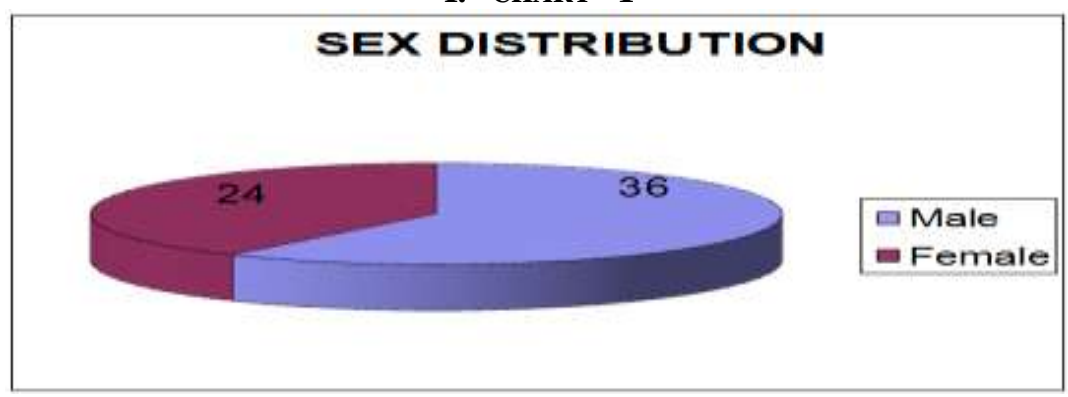


II. CHART - 2

1) Showing various Age groups and its distribution

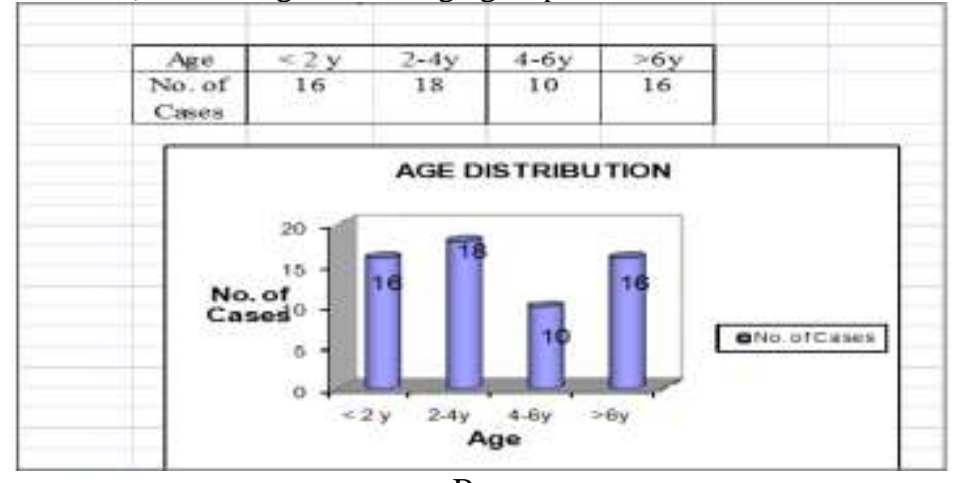

B.

\section{1. Empyema thoracis:}

Number of patients treated - 40

This study has reviewed the records of 40 patients who were diagnosed as pyothorax. Most of the patients were received from corresponding medical unit or referred from other hospitals as empyema thoracis.

4.1.1 Procedure: Patient received general anaesthesia, endotracheal tube with controlled ventilation. Patient placed in lateral decubitus position with diseased side upwards. ${ }^{[1,2]}$ Patient received two to four ports according to the needs. Depending on the stage of the disease either thoracoscopy alone or thoracoscopy followed by open thoracotomy was done if fibrothorax was present. Intercostal drain placed through one of the port sites Pus sent for routine examination and culture. ICD removal done after three to five days. Follow-up chest X-rays taken.

$\begin{array}{lcc}\text { The average duration of ICD } & - & 3.7 \text { days } \\ \text { Post op Analgesia } & - & 2.5 \text { days } \\ \text { Ambulation } & - & 3.1 \text { days }\end{array}$

\subsection{Pyopericardium:}

Number of patients: 6 This study has analysed three patients with pyopericardium managed thoracoscopically by the way of window pericardiectomy. All the three patients were investigated and evaluated with chest X-ray, ECG and Echo cardiography and found to have moderate amount of pericardial collection. Patient was posted in an elective list. None of the procedure was done in the semi emergency setting.

4.2.1Procedure: GA, with endotracheal tube, conventional method, lateral decubitus position, left side up, three ports introduced, $10 \mathrm{~mm}$ camera port in two patients and $4 \mathrm{~mm}$ camera port in one. Two working ports $(5 \mathrm{~mm})$ in fourth intercostal space were introduced. Adhesions between lung, pericardium and chest wall were removed. One patient had purulent material in the pleural cavity as well, which was removed. Pericardium was fenestrated with the help of scissors. Pus drained, window was made bigger with the help of monopolar diathermy. Pleural cavity drained by chest tube. Post operative period was uneventful.

ICD kept for 3 days

Analgesic requirement 2.3 days

Ambulation 3 days.

\subsection{Congenital Diaphragmatic Hernia (Bockdolek): Number of patients: 4}

This study has retrospectively analysed the records of two patients who were managed by thoracoscopic repair. One was a newborn presenting with respiratory distress and the other was a 4 year old presenting with recurrent respiratory tract infection.

4.3.1Procedure: GA, endotracheal tube, controlled ventilation, conventional anaesthesia, in lateral decubitus position, left side up, three ports used. $4 \mathrm{~mm}$ and $10 \mathrm{~mm}$ camera ports were used in the newborn an the 4 year old respectively. A fourth port introduced without trocar for holding sutures. Contents were reduced with pneumothorax and with forceps. Mobilisation of the posterior lip was done and repair done with 3-0 ethibond continuous sutures and 2-0 ethibond interrupted reinforcing sutures. ICD kept. 
Number of patients: 2 This study has retrospectively analysed the records of one patient who was managed by thoracoscopic plication of right diaphragm. Patient had presented with recurrent respiratory infection. Diagnosis was confirmed by $\mathrm{x}$-ray chest and CT.

4.4.1 Procedure: GA, endotracheal tube, controlled ventilation, conventional, in left lateral decubitus position, three ports used. $10 \mathrm{~mm}$ camera port, and two $5 \mathrm{~mm}$ working ports used. Pneumothorax created upto $8 \mathrm{~mm}$. Diaphragm plicated with 3-0 prolene continuous sutures. ICD kept.

\subsection{Bronchogenic cyst:}

Number of patients: 2This study has retrospectively analysed the records of one patient who was managed by thoracoscopic excision. Patient has presented with fever and respiratory infection. Diagnosed with chest X-ray and CT scan.

4.5.1 Procedure: GA, endotracheal tube, controlled ventilation, conventional, in left lateral decubitus position, three ports used. $10 \mathrm{~mm}$ camera port, and two $5 \mathrm{~mm}$ working ports. Pneumothorax created upto 8 $\mathrm{mm}$. Thoracic cyst found in the right apex. Purulent material aspirated. Cyst dissected all around, decompressed and excised using diathermy. No communication to bronchus noted. ICD kept.

\subsection{Foregut duplication cyst:}

Number of patients: 2 This study has analysed the records of one patient who was managed by thoracoscopic excision. Patient has presented with recurrent respiratory tract infection and severe dyspnoea. Investigated with chest X-ray and CT scan which showed cystic lesion in the mediastinum.

4.6.1 Procedure: GA, endotracheal tube, controlled ventilation, conventional, in left lateral decubitus position, three ports used. $10 \mathrm{~mm}$ camera port, and two $5 \mathrm{~mm}$ working ports. Pneumothorax created upto $8 \mathrm{~mm}$. Mediastinal pleura opened. Cyst aspirated. Cyst wall grasped and completely excised with diathermy. No communication to esophagus noted. ICD kept.

\subsection{Mediastinal Node biopsy:}

Number of patients: 2 This study has retrospectively analysed the records of one patient who was managed by thoracoscopic node biopsy. Patient has presented with persistant fever. Investigations were noncontributory except for CT chest showing mediastinal widening.

4.7.1 Procedure: GA, endotracheal tube, controlled ventilation, conventional, in left lateral decubitus position, three ports used. $10 \mathrm{~mm}$ camera port, and two $5 \mathrm{~mm}$ working ports. Pneumothorax created upto 8 $\mathrm{mm}$. Mediastinal pleura opened. Enlarged lymph nodes identified and dissected. Node removed in toto. ICD kept.

\subsection{Esophageal Atresia with TEF:}

Number of patients: 2 This study has retrospectively analysed the records of one patient who was managed by thoracoscopic converted to open fistula ligation with end to end esophageal anastomosis.

4.8.1 Procedure: GA, endotracheal tube, controlled ventilation, conventional, in left lateral decubitus position, three ports used. $4 \mathrm{~mm}$ camera port and two $5 \mathrm{~mm}$ working ports. Pneumothorax created with $6 \mathrm{~mm}$ $\mathrm{CO}_{2}$. Esophageal atresia with distal fistula was made out. Azygous vein identified and mobilized. Upper pouch identified and mobilized. Distal TEF identified and mobilized. Due to lack of space and haemodynamic instability, converted to open. Open procedure done by conventional method. ICD kept.

\section{4.9Comparative Analysis}

The various results and observations made from this study were compared with similar studies and the outcome is discussed here. The feasibility and safety of VATS in children has been shown in several series.

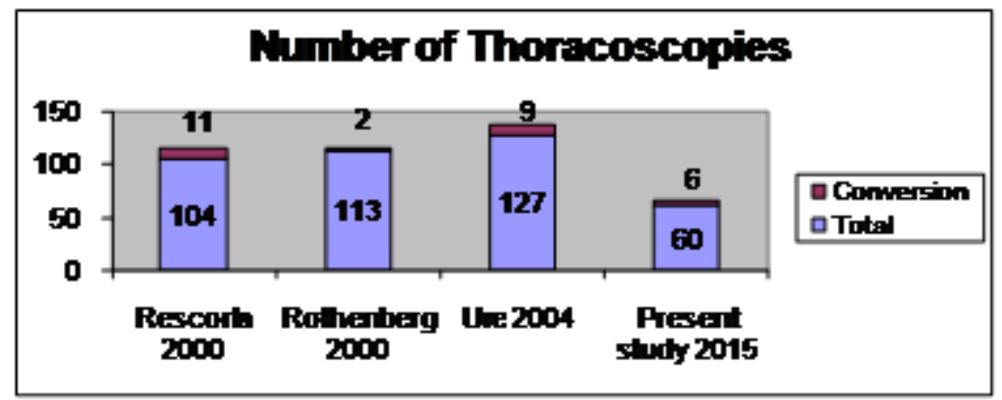

Conversion rate according to this series is 7 to $11 \%$

(i) Conversion rate in the present study is $10 \%$ 
(ii)

Empyema Thoracis ( Management algorithm)

According to one study from Journal of Indian Association of Paediatric Surgery (July - Sep 2005) The management consensus is according to the duration of illness and Stage of Diseases ${ }^{[3,4]}$

Stage I - $\quad$ ICD Drainage

Stage II - $\quad$ VATS Decortication

Stage III - $\quad$ Open Decortication

The present study has similar management protocol except that in the later part of the study there is a trend towards primary VATS decortication. Duration of Illness \& Management Another study from mumbai which done between June 2000-Dec $2002^{14}$, had managed 14 patients of pyothorax.

\begin{tabular}{|l|l|l|}
\hline Duration & Thoracoscopic decortication & VATS + Open Decortication \\
\hline $\begin{array}{l}<1 \text { week } \\
10 \text { cases }\end{array}$ & $8(80 \%)$ & $2(20 \%)$ \\
\hline $\begin{array}{l}>1 \text { week } \\
4\end{array}$ & $1(25 \%)$ & $3(75 \%)$ \\
\hline
\end{tabular}

Present Study

\begin{tabular}{|l|l|l|}
\hline Duration & Thoracoscopic decortication & VATS + Open Decortication \\
\hline $\begin{array}{l}<1 \text { week } \\
11 \text { cases }\end{array}$ & $18(82 \%)$ & $4(18 \%)$ \\
\hline $\begin{array}{l}>1 \text { week } \\
9 \text { cases }\end{array}$ & $6(33 \% 0$ & $12(67 \%)$ \\
\hline
\end{tabular}

When we compare both the studies the result are similar. If the patients seeks medical help earlier within 1 week, the condition is managed with thoracoscopic Decortication. If the duration is more than 1 week, the management depends upon the stage of the disease and most of the patients will require open thoracotomy which increases the morbidity of the patient. VATS has been used in children for debridement of the pleural space failing conventional management ${ }^{15}$

A retrospective study done at DALLS, TEXAS between Jan 1992 to July 1998, Which showed the following results.

They divided the patient into 3 groups according to the management algorithm.

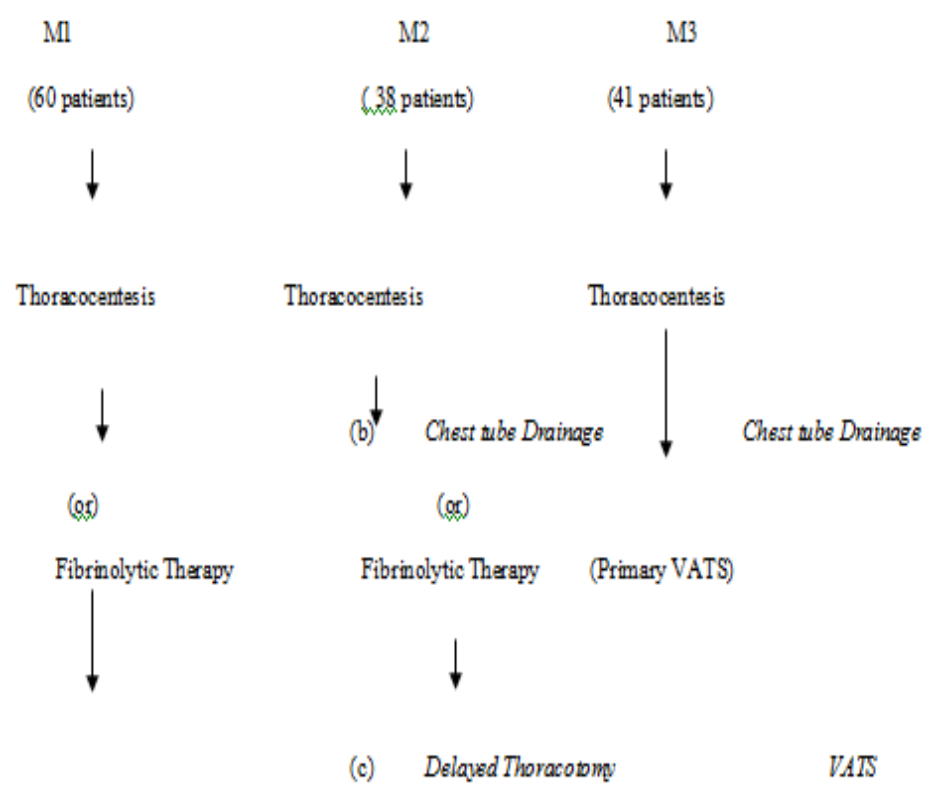

From their study they have analysed that the median length of stay in Hospital was significantly lower. The duration of ICD tube drainage is also significantly reduced in patients who have been managed with primary VATS. 


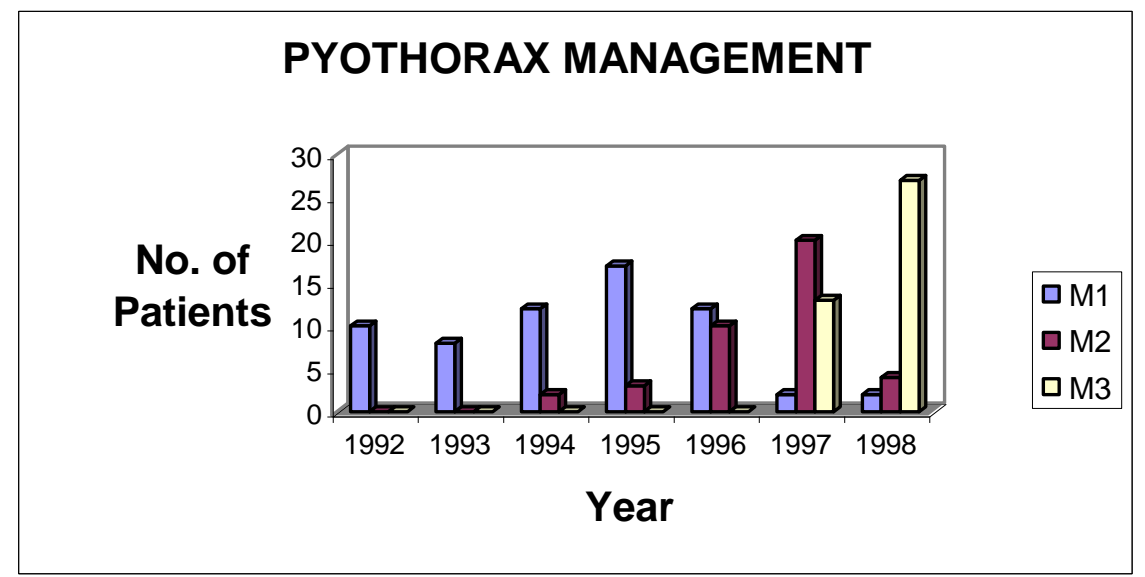

This figure shows that the trend in the management of Empyema Thoracis shifting towards Primary VATS.

The present study is also has similar trend in the management of Empyema Thoracis.

Initially the patients referred to the study center with chest tube placed already. The management sequence is as follows:

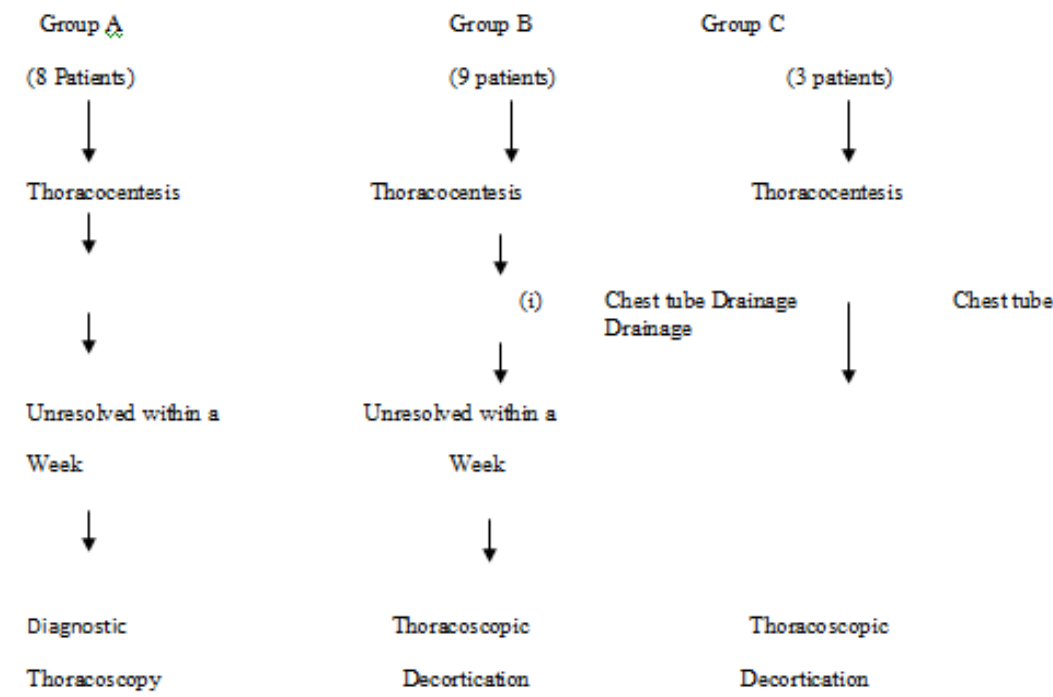

If we look at the later part of the study the trend is toward primary VATS as the patients are referred earlier without chest tubes.

\begin{tabular}{|c|c|c|c|c|}
\hline \multirow{2}{*}{$\begin{array}{llll} & & \\
\begin{array}{l}\text { Duration of } \\
\text { (days) }\end{array} & \text { Chest tube } \\
\end{array}$} & \multicolumn{3}{|c|}{$\begin{array}{lc}\text { 2) } \quad \mathrm{A} & \mathrm{B} \\
\text { (16 Patients) } & \text { (18 Patients) } \\
\text { Average (days) } & \end{array}$} & \multirow{2}{*}{$\begin{array}{l}\text { P value } \\
-\end{array}$} \\
\hline & 5 & 3.7 & 2.3 & \\
\hline Length of stay (days) & 8.6 & 5 & 4 & - \\
\hline
\end{tabular}

When we compare the study group with above study the number of days with chest tube, Early ambulation is similar to that of above group. Primary thoracoscopy has a better outcome when compared to other procedures. Since the study group is very small ' $\mathrm{P}$ ' value is statistically insignificant.

Results of VATS in the Treatment of Paediatric empyema. 


\begin{tabular}{|c|c|c|c|c|c|c|}
\hline Reference & $\begin{array}{l}\text { Patients } \\
\text { (N) }\end{array}$ & $\begin{array}{l}\text { Preoperative } \\
\text { Chest tube } \\
\text { (Days) }\end{array}$ & $\begin{array}{l}\text { Postoperative } \\
\text { Chest tube } \\
\text { (days) }\end{array}$ & $\begin{array}{l}\text { Postoperative } \\
\text { LOS (Days) }\end{array}$ & $\begin{array}{ll}\text { Total } & \text { LOS } \\
\text { (Days) } & \end{array}$ & $\begin{array}{l}\text { Recurrence, } \\
\text { Failure, or } \\
\text { Death }(\mathrm{N})\end{array}$ \\
\hline $\begin{array}{l}\text { Kern \& Rodgers } \\
(1993)\end{array}$ & 9 & $6.9 \pm 1.8$ & $8.4 \pm 4$ & $13.4 \pm 2.9$ & NA & 1 \\
\hline $\begin{array}{ll}\text { Stovroff } & \text { et.al. } \\
(1995) & \end{array}$ & 12 & 4 to 6 & 4 & 6 to 8 & NA & 0 \\
\hline $\begin{array}{l}\text { Silen \& } \quad \text { Weber } \\
(1995)\end{array}$ & 3 & $4 \pm 1$ & $7 \pm 1$ & $8 \pm 1$ & NA & 0 \\
\hline $\begin{array}{ll}\text { Davidoff } & \text { et.al. } \\
(1996) & \end{array}$ & 9 & NA & 8.5 & NA & NA & 2 \\
\hline 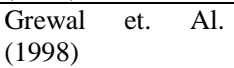 & 25 & $2 \pm 1.6$ & $3.2 \pm 2.2$ & $4.9 \pm 2.7$ & $7.3 \pm 4$ & 0 \\
\hline $\begin{array}{ll}\text { Present } & \text { study } \\
(2015) & \end{array}$ & 24 & 4 to 6 & 3.7 & 6 to 8 & NA & 1 \\
\hline
\end{tabular}

\section{Pyopericardium}

A prospective study conducted at Central Hospital for children at Vietnam. July 2002 - June 2004. which showed the length of hospital stay is reduced when pyopericardium is managed by thoracoscopic approach, without much complications.

(i) Management of Pyopericardium Table :

\begin{tabular}{|l|l|l|l|}
\hline Length of Hospital stay & $\mathbf{1 - 4}$ days & $\mathbf{4 - 1 0}$ days & $>10$ days \\
\hline No. of Patients & 15 & 7 & 2 \\
\hline Present Study & - & 6 & - \\
\hline
\end{tabular}

\section{CDH - Thoracoscopic Approach}

A retrospective study conducted at Ann Arbor, Michigan. Revealed the following data. ${ }^{[5,6]}$

\section{Bochdalek Hernias}

This study reveals that CDH repair in non new borns is a reasonable option. Thoracoscopy is a better approach for repairing the hernia when compared to laparoscopy. But new borns CDH repair should be approach cautiously because of the chances of recurrence and attended complications. But in the present study there are no recurrences and complications. Patient had a very quick recovery.

A study from division of paediatric surgery of St. Justin Hospital Montreal, Quebec, Canada ${ }^{[7]}$, which revealed that the Thoracoscopic approach of excision of Isolated duplication cyst has reduced number of chest tube days and hospital stay when compared to thoracotomy.

\section{Excision Of Isolated FD Cysts}

\begin{tabular}{|l|l|l|l|l|}
\hline & $\begin{array}{l}\text { Thoracotomy } \\
(\mathbf{n = ~ 1 6})\end{array}$ & Thoracoscopy & $\mathbf{P}$ & Present Study \\
\hline Chest tube duration (d) & $3.3 \pm 0.4$ & $1.6 \pm 0.5$ & .01 & 4 \\
\hline $\begin{array}{l}\text { Postoperative length of } \\
\text { stay (d) }\end{array}$ & $6.6 \pm 1.0$ & $2.6 \pm 0.5$ & .002 & 6 \\
\hline
\end{tabular}

But in the present study the number of chest tube days has not reduced significantly but the attended morbidity and analgesic requirement is reduced significantly. In most of the reported series the complications in Thoracoscopy are very minimal and are mostly related to Anaesthesia. In our series most of the patient undergone dual lung ventilation with conventional anaesthesia without much complications.

\section{Post operative complications:}

Prolonged air leak -1

Residual disease -1

Even though there are two mortality in this series which are unrelated to thoracoscopic procedures

\section{Conclusion}

Thoracoscopy is definitely superior to thoracotomy in the management of Empyema thoracis in relation to

a. Pain relief

b. Morbidity

c. Early recovery 
d. Requirement of blood transfusion

Primary VATS has a role in the management of empyema thoracis. Thoracoscopy can safely be done in all age groups and even in very sick children. This study reveals that this is an excellent procedure for mediastinal biopsy with a very high yield. This study reveals that thoracoscopy reduced the morbidity and gives better cosmetic results in case of pyopericardium. This study also reveals that it definitely reduces the morbidity and hospital stay in cases of thoracoscopic CDH repair. Cystic lesion of the lung can be excised safely and effectively by thoracoscopy. This study reveals that procedure like thoracoscopic esophageal atresia repair needs more operative time and expertise with specialized instruments. This study also reveals that thoracoscopic procedures can be done with conventional dual lung ventilation with pneumothorax. One lung ventilation or double lumen tubes are not mandatory. This study reveals that complications encountered in thoracoscopy are usually minor.

\section{Bibliography}

[1]. Klimkovich, IG, Geldt, VG, Okulor, AB et al. Thoracoscopy in children. Khiruvgila (mosk) 47 : 19-24 1972

[2]. Klimkovich, IG, Geldt, VG, Okulor, AB et al. Thoracoscopy in children. Khiruvgila (mosk) $47: 19-241972$

[3]. Antony VB, Mohamed KA. Patho physiology of pleural space infections. Semin. Respiratory infection 1999, 14:9-7

[4]. Klena TW, Cameron BH, Langer JC et al; timing of video -assisted Thoracoscopic debridement for paediatric empyema. J. Am. coll. suag 187:404-408, 1998

[5]. Clark RH, Hardia Jr WD, Hirschl RB et al, currant surgical Management of CDH. A report from CDH study group J. Paed. Surgery 1998:33, 1004-9.

[6]. Area MJ. Bamhart DC, Lelli JL et al; Thoracoscopic Treatment for delayed presentation of CDH in the infant results and lessons learned

[7]. J. Paediatric surgery 2003; $38: 1563$ - 8, MERRYe, Spurbeck W, LobeTE : Resection of foregut derived duplications by minimal access surgery. Paed. Surgery int. 1999:15:224-6 